\title{
The Herpetofauna of Adana Province (Turkey)
}

\author{
Burhan SARIKAYA, Mehmet Zülfü YILDIZ2,* Göksal SEZEN³
}

1Fatih Anatolian High School, Ministry of National Education, Adryaman, Turkey

2Zoology Section, Department of Biology, Faculty of Arts and Sciences, Adiyaman University, Adryaman, Turkey

3 Hydrobiology Section, Department of Biology, Faculty of Arts and Sciences, Harran University, Şanluurfa, Turkey

\begin{tabular}{l} 
Received: $25.11 .2017 \quad$ Accepted: $21.12 .2017 \quad$ Available online: 25.12 .2017 \\
\hline Abstract: In this study, it is aimed to determine the amphibians and reptiles species of Adana province. This study was \\
conducted in September and October 2013 and February, March, May, April, and June 2014. As a results of the study, 4 anuran \\
species belonging to three families, 2 urodelian species belonging to one family, 6 tortoise species belonging to five families, 16 \\
lizards species belonging to 6 families, one worm lizard, 19 snakes species belonging to 4 families, with a total of 48 different \\
species of amphibians and reptiles, showing distribution in Adana, were identified. However, the species of Neurergus strauchii, \\
Pelobates syriacus, Anatololacerta pelasgiana, Darevskia valentini, Eirenis decemlineatus, E. eiselti, E. lineomaculatus, Rhynchocalamus \\
melanocephalus, which were recorded in the literature previously, could not be found. With the field survey and literature \\
records, 56 amphibian and reptile species belonging to 21 families were determined in Adana province. In addition, chorotype \\
information of the species and distribution localities in Adana were given in detail.
\end{tabular}

Keywords: Anatolia, biodiversity, amphibia, reptilia, distribution

\section{Adana İlinin Herpetofaunas1}

Özet: Bu çalışma ile Adana ilinde dağılış gösteren kurbağa ve sürüngen türlerinin belirlenmesi amaçlanmıştır. 2013 yılında; Eylül ve Kasım aylarında, 2014 yılında ise Şubat, Mart, Nisan, Mayıs ve Haziran aylarında yapılan arazi çalışmaları sonucunda Adana ilinde 3 familyaya ait 4 anur türü, bir familyaya ait 2 semender türü, 5 familyaya ait 6 kaplumbağa türü, 6 familyaya ait 16 kertenkele türü, bir kör kertenkele ve 4 familyaya ait 19 yılan türü olmak üzere toplam 48 farklı kurbağa ve sürüngen türü tespit edilmiştir. Literatür kayıtlarında tespit edilen Neurergus strauchii, Pelobates syriacus, Anatololacerta pelasgiana, Darevskia valentini, Eirenis decemlineatus, E. eiselti, E. lineomaculatus, Rhynchocalamus melanocephalus türleri ise arazi çalışmalarında bulunamamışır. Arazi çalışmaları ve literatür kayıtları ile Adana ilinde 21 familyaya ait 56 kurbağa ve sürüngen türünün Adana'da dağılış gösterdiği belirlenmiştir. Ayrıca türlere ait korotip bilgileri ve Adana'da dağılış gösterdiği lokaliteler detaylı olarak verilmiştir.

Anahtar kelimeler: Anadolu, biyoçeşitlilik, kurbağa, sürüngen, dağılış

\section{Giriş}

Yurdumuz, diğer türlerde olduğu gibi kurbağa ve sürüngen türlerinin de adeta harmanlandığı eşsiz bir kara parçasıdır. Dolayısıyla ülkemiz kurbağa ve sürüngen çeşitliliği açısından da oldukça zengindir. Ülkemiz herpetofaunası halen tam olarak belirlenemediğinden her geçen yil yeni herptil türleri tanımlanmakta veya yeni kayıtlar verilmektedir (Kumlutaş ve ark. 2007, Göçmen ve ark. 2011, Yalçınkaya ve Göçmen 2012, Göçmen ve Akman 2012, Yildız ve İğci 2015a, İğci ve ark. 2015b, Bülbül ve ark. 2016). Bu nedenle, son y1llarda, belli bir bölgede yaşayan kurbağa ve sürüngen türlerinin tespitine yönelik çalışmalar hız kazanmıştır (Özdemir ve Baran 2002, Kumlutaş ve ark. 2004, Afşar ve Tok 2012, Özcan ve Üzüm 2013, Cihan ve Tok 2014, Ege ve ark. 2015, Eksilmez ve ark. 2017, Kumlutaş ve ark. 2017). Yapılan son çalışmaların değerlendirilmesi sonucu, ülkemizde 31 kurbağa ve 137 sürüngen türü olmak üzere toplam 168 herptil türünün yaşadığı tespit edilmiştir (Sindaco et al. 2000, Yıldız ve İğci 2015, Bülbül ve ark. 2016, Veith et al. 2016).

13915 km2 yüz ölçümüne sahip Adana ilinde, deniz, lagünler nehirler, göller, ovalar ve yüksek dağlar gibi birçok coğrafik yapı bulunmaktadır. Bu farklı coğrafik yapıya uygun olarak farklı habitatlar da, farklı iklim özelliği göstermektedir. İl sınırları içerisinde bulunan alanların rakımı 0 ile $3700 \mathrm{~m}$ arasında değişmektedir. 160 kilometrelik kıyı şeridi, Ceyhan ve Seyhan nehirleri ve üzerinde kurulu barajlar ile sulak alanlar, denize dökülen nehirlerin yaptığı deltalar ve lagünlerden dolayı Adana ili büyük bir biyoçeşitliliğe ev sahipliği yapmaktadır (Anonim 2013).

Adana ilinde dağılış gösteren amfibi ve sürüngen türleri ile ilgili birçok çalışma yürütülmüş olup yapılan çalışmaların çoğunda bir veya birkaç tür ele alınmış, bazılarında ise sadece türlerin dağılış bilgileri rapor edilmiştir (Kumlutaş 1993, Schmidtler ve Bischoff 1995, Kaya 2001, Yıldız ve ark. 2007, Ayaz ve ark. 2008, 2011, Karahisar ve Demirsoy 2012, Göçmen ve ark. 2013). Adana ili kurbağa ve sürüngenlerinin rapor edildiği ilk çalışmalar Werner (1919), Bird (1936), Eiselt (1940), Zaloğlu (1968) ve Zinner (1972) tarafından gerçekleştirilmiştir. Bu çalışmaları, Salamandra infraimmaculata (Öz 1987), Bufotes variabilis (Tosunoğlu 1996) türleri gibi çeşitli kurbağa ve sürüngen türleri hakkında yapılan çalışmalar takip etmektedir.

Adana ilinin tüm kurbağa ve sürüngenleri ve bu türlere ait ekolojik-biyolojik özellikleri kapsayan detaylı bir çalışma günümüze kadar yapılmamıştır. Bu çalışma ile daha önce detaylı bir araştırma yapılmamış ve tür 
listesi çıkarılmamış olan Adana ilinin herpetofaunasının belirlenmesi amaçlanmıştır.

\section{Materyal ve Metod}

$\mathrm{Bu}$ çalışma için; Adıyaman Üniversitesi Zooloji Müzesi (ZMADYU) envanterine kayıtlı Adana örnekleri ile arazi çalışmaları sonucu tespit edilen örnekler kullanılmıştır. Çalışma kapsamında 2013 ve 2014 yıllarında 34 günlük arazi çalışması düzenlenmiş ve çalışma alanında 413 farklı lokalitede gözlem yapılmıştır. Bunlardan 326'sında kurbağa türleri, 327'sinde de sürüngen türleri gözlenmiştir. Ancak verilerin daha verimli kullanılabilmesi ve haritada gösterilebilmesi için 3-5 km² alanda yapılan tüm gözlemler tek noktada birleştirilmiş ve 118 lokalite olarak Şekil 1'de gösterilmiştir. Arazi çalışmaları, kurbağa ve sürüngenlerin en aktif oldukları Eylül 2013-Haziran 2014 ayları arasında gerçekleştirilmiştir. Adana ilinin 1/25000 ölçekli haritasında bulunan 106 pafta'nın herbirinde en az 1 örnekleme yapılarak çalışmanın tüm ili kapsaması sağlanmıştır. 2013 yılında; Eylül ve Kasım aylarında, 2014 yılında ise Şubat, Mart, Nisan, Mayıs ve Haziran aylarında arazi çalışmaları yapılmıştır. Gözlem yapılan lokalitelere ait detaylı veriler Ek-1'de verilmişir.

Arazi çalışmaları planlanırken; Google Earth programından habitatlar incelenmiş ve sürüngenler ve kurbağalar için uygun olan sulak ve karasal habitatlar belirlenmiştir. Ayrıca yapılan literatür taraması sonucu, literatürde yer alan lokaliteler de arazi çalışmaları sırasında kontrol edilmiştir. Habitatın büyüklüğüne göre her istasyonda $10 \mathrm{dk}$ ile 1,5 saat arasında arazi çalışması yapılmıştır. Arazi gezileri genellikle 3-4 kişilik bir ekip ile gerçekleştirilmiştir. Sürüngen örnekleri eldiven kullanılarak elle toplanmıştır. Kurbağalar ise elle ve kepçe yardımı ile tolanmıştır. Toplanan örnekler arazi çalışmasının sonuna kadar, vücut ölçüm oranları ve pholidosis özelliklerinin belirlenmesi için bez torbalar içerisinde saklanmıştır. Toplanan örneklere ait renk ve desen özelliklerini kaydetmek amacıyla, örnekler canlı iken fotoğrafları dijital fotoğraf makinesi (Nikon D300S) ile çekilmiştir. Türlerin tanımlanması güncel literatürden faydalanılmıştır. Nokturnal (gececi) sürüngen türlerinin bulunabilmesi için en uygun habitatlarda gece arazi çalışmaları gerçekleştirilmiştir. Arazi çalışmaları esnasında, örnek tespit edilen habitatların, yükseklik ve koordinatları GPS (Global Positioning System) cihazı (Garmin GPS map 62sc; evrensel enlem markatörü olarak) ile alınmış ve nuhun gemisi veri sistemine kaydedilmiştir.

Tespit edilen türler, Avrupa yaban hayatı ve yaşam ortamlarının korunması (BERN) sözleşmesi (Bern 1982), nesli tehlikede olan yabani hayvan ve bitki türlerinin uluslararası ticaretine ilişkin sözleşmesi (Cites 1975) ve Dünya doğa ve doğal kaynakları koruma birliği tarafından (IUCN) tarafından belirlenen, nesli tükenme tehlikesi altında olan türlerin kırmızı listesine göre kategorileri belirlenmiştir (IUCN 2017).

\section{Sonuçlar ve Tartışma}

Adana ili ile ilgili yapılan daha önceki çalışmalarda, Pelophylax ridibundus s.l, Bufotes variabilis, Rana macrocnemis, Hyla savignyi, Salamandra infraimmaculata, Ommatotriton vittatus, Neurergus strauchii ve Pelobates syriacus olmak üzere 8 kurbağa türü rapor edilmiştir (Venzmer 1922, Bird 1936, Eiselt 1966, Clark ve Clark, 1973, Atatür 1974, Öz 1987, Arıkan ve ark. 1990, Teynie 1991, Başoğlu ve ark. 1994, Riehl ve ark. 1995, Steinfartz 1995, Arıkan ve ark. 2000, Franzen ve Schmidtler 2000, Franzen, 2000, Arntzen ve Olgun 2000, Jdeidi ve ark. 2001, Plötner ve ark. 2001, Uğurtaş 2001, Veith ve ark. 2003, Göçmen ve ark. 2008, Karahisar ve Demirsoy 2012). Yapılan arazi çalışmaları sonucunda $P$. ridibundus en yaygın anur türü olarak tespit edilmiş, bunu Hyla savignyi ve $B$. variabilis takip etmiştir. $\mathrm{Bu} 3$ anur türü özellikle alçak rakımlı alanların tamamında simpatrik olarak gözlenmiştir. Yüksek rakımlarda gözlenen R. macrocnemis Adana ilinde en az gözlenen anur türüdür. Arazi çalışmaları sırasında gözlenemeyen tek anur türü $P$. syriacus, toprak kurbağasıdır. Adana ilinin özellikle kuzey kesimlerinde dağılış gösteren S. infraimmaculata en fazla gözlenen kuyruklu kurbağa türüdür. Mertens (1952), Adana ilinden Neurergus strauchii'ye ait 4 larvayı rapor etmiştir. Ancak bu çalışma süresince yapılan arazi çalışmaları sırasında, türün herhangi bir formu (larva, juvenil veya ergin) bulunamamışır. Çalışma alanı olan Adana ilinin özellikle, kuzey kesimlerinde Feke, Saimbeyli ve Tufanbeyli ilçelerinde $N$. strauchii için uygun biyotoplar mevcuttur. Adana ilinden rapor edilen kurbağalardan 6 tür için birçok yeni lokalite belirlenmiştir (Tablo 1).

Adana ilinde 48 sürüngen türünün dağılış gösterdiği çeşitli çalışmalar ile rapor edilmiştir (Bird 1936, Clark ve Clark 1973, Fritz ve Freytag 1993, Fritz ve Wischuf, 1997, Mulder 1995, Schmidtler 1998, Sindaco ve ark. 2000, Ayaz ve ark. 2006, Schmidtler ve ark. 2009). Bu sürüngenlerden altı kaplumbağa türünün yaşadığı tespit edilen Adana ilinde, karasal habitatlarda Testudo greaca, tatlısularda ise Mauremys rivulata türleri bu çalışmada 30 civarında habitatta tespit edilerek oldukça yaygın oldukları gözlenmiştir. Trionyx triunguis, Emys orbicularis, Chelonia mydas ve Caretta caretta ise birer lokalitede tespit edilmiştir (Tablo 1). Deniz Kaplumbağalarının tespiti için yumurtlama döneminde, Kapıköyü Karataş mevkiinde gece arazi çalışması yapılmış ve yumurtlamaya çıkan dişi bireyler gözlenmiştir. Çalışma alanında toplam 20 kertenkele türü tespit edilmiştir. Bunlardan, Stellagama stellio, Ophisops elegans, Lacerta media ve Phoenicolacerta laevis en yaygin gözlenen kertenkele türleridir (Tablo 1). Ülkemizdeki Blanus populasyonları, son yıllara kadar $B$. s. strauchi ve B. s. aporus olarak iki alt tür halinde ele alınmıştır (Baran 1977b). Sindaco ve ark. (2014) Adana, Hatay, Gaziantep ve Mardin'den topladıkları örnekler ile Blanus alexandri türünü tanımlamış ve aynı çalışmada $B$. s. aporus'u tür seviyesine çıkarmıştır. Yaptıkları çalışmada $B$. alexandri ile $B$. aporus arasinda net bir morfolojik farklılığın olmadığı sadece $B$. alexandri'nin daha yüksek vücut halkasına ve daha düşük dorsal ve ventral pullara sahip olması ile $B$. aporus'tan ayrılabileceği rapor edilmiştir. Bu çalışmada toplanan örnekler vücut halka sayıları açısından $B$. aporus türüne, vücut etrafındaki pul sayısı açısından ise $B$. alexandri türüne daha yakındır. Aynı çalışmada iki türün İçel ile Kozan ilçeleri arasında bir yerde ayrılabileceği ifade edilmiştir. 


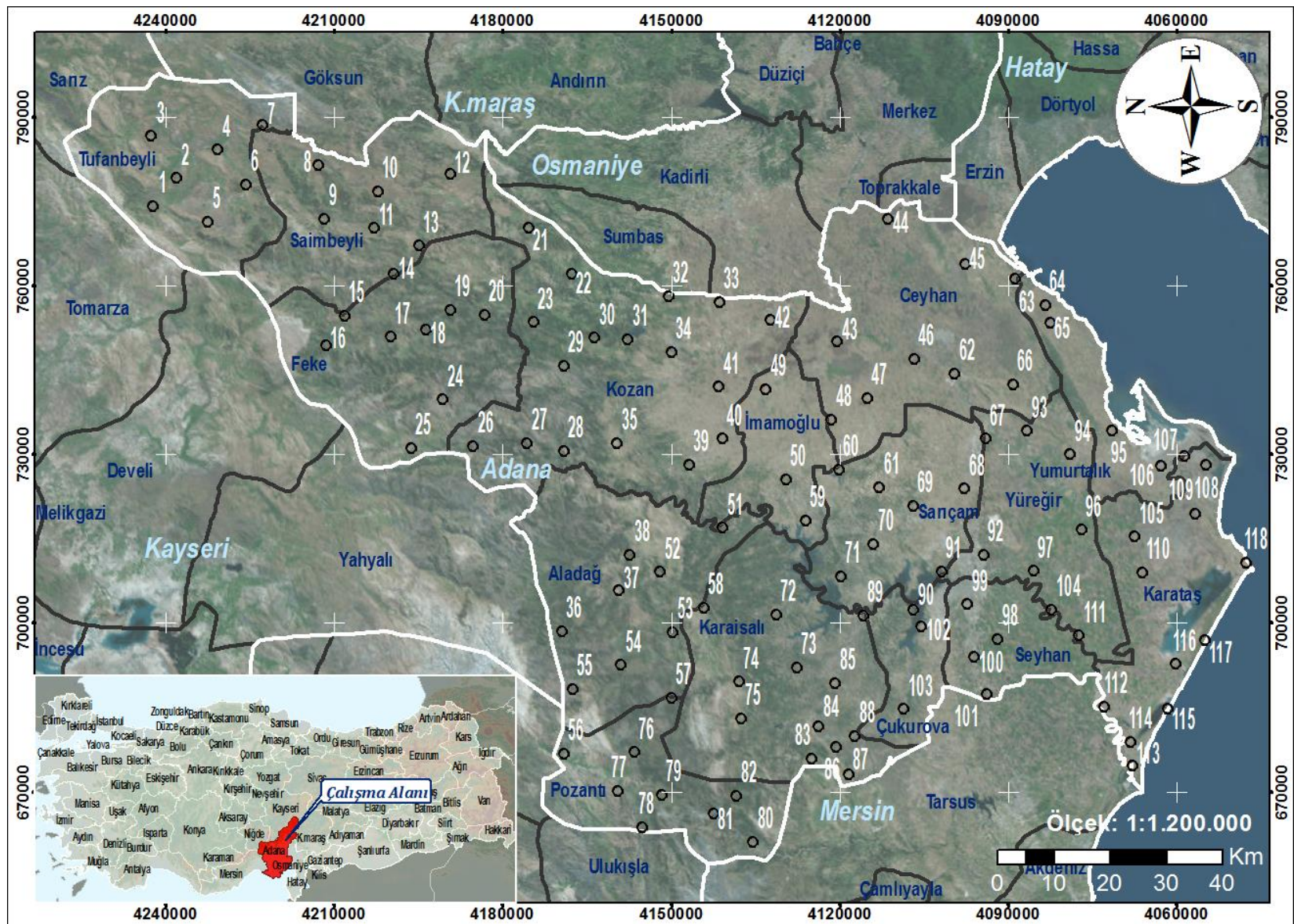

Şekil 1: Adana ilinde arazi çalışmaları yapılan lokaliteler: 1-Tozlu/Tufanbeyli 09.06.2014-1522 m., 2- Damlalı/Tufanbeyli 09.06.20141510 m., 3- Polatpınar/Tufanbeyli 09.06.2014-1377 m., 4- Yamanl//Tufanbeyli 09.06.2014-1357 m., 5- Çatalçam/Tufanbeyli 09.06.20141553 m., 6- Güzelim/Tufanbeyli 10.04.2014-1377 m., 7- Çukur/Tufanbeyli 09.06.2014-1465 m., 8- Yeniköy/Saimbeyli 09.06.201-1531 m., 9- Saimbeyli 10.04.2014-823 m., 10- Eyüplü/Saimbeyli-1483 m., 11- Gürleşen/Saimbeyli 21.09.2013-804 m., 12- Halilbeyli/Saimbeyli 08.05.2014-1339 m., 13- Himmetli/Saimbeyli 21.09.2013-663 m., 14- Çıvıklı/Saimbeyli 10.06.2014- 1148 m., 15- Çorak/Feke 10.06.20141160 m., 16- Kayhan/Feke 10.06.2014-1045 m., 17-Bağdatlı/Feke 10.06.2014-935 m., 18- Belenköy 10.06.2014- 799 m., 19- Feke 21.09.2013631 m., 20- Akkaya/Feke 09.04.2014-771 m., 21- Akçalıuşă̆ı/Kozan 08.05.2014-1383 m., 22- Boztahta/Kozan 08.05.2014-699 m., 23Çulluuşağı/Kozan 09.04.2014-587 m., 24- Kaleyüzü/Feke 10.06.2014-1095 m., 25- Mansurlu/Feke 10.06.2014-1464 m., 26Akkaya/Kozan 10.06.2014-1392 m., 27- Marankeçili/Kozan 10.06.2014-1411 m., 28- Ergenuşağ1/Kozan 10.06.2014-477 m., 29Camdere/Kozan 10.04.2014-650 m., 30- Karamusalı/Kozan 21.09.2013-427 m., 31-Baraj/Kozan 09.04.2014-317 m., 32- Ilica/Kozan 07.05.2014-209 m., 33- Aydınlı/Kozan 07.05.2014-128 m., 34- Kozan 08.06.2014-765 m., 35- Akdam/Kozan 08.06.2014-765 m., 36Soğukoluk/Aladağ 26.06.2014-1438 m., 37-Kabasakal/Aladağ 12.04.2014-715 m., 38- Aladağ 12.04.2014-944 m., 39- K1zılhöyük/Kozan 08.06.2014-423 m.,40- Damyeri/Kozan 08.06.2014 -199 m., 41- ̇̇demköy/Kozand 08.06.2014-120 m., 42- Gazi/Kozan 07.05.2014-45 m., 43Çatalhöyük/Ceyhan 06.04.2014-34 m., 44- Tatarlı/Ceyhan 06.04.2014-38 m., 45- Selimiye/Ceyhan 15.03.2014-185 m., 46- Ceyhan 18.03.2014-30 m., 47- Dumlu/Ceyhan 07.04.2014-61 m., 48- Gümüdürlü/Ceyhan 07.04.2014-77 m., 49- Ufaçıkören/İmamoğlu 08.06.201470 m., 50- Sevinçli/Sarıçam 07.04.2014-164 m., 51- Sanaklı/Aladă̆ 09.04.2014-241 m., 52- Meydan Yaylasi/Aladağ 12.04.2014-1183 m. 53- Posyağbasan/Aladağ-934 m., 54- Büyüksofulu/Aladağ 11.05.2014-1047 m., 55- Büyüksofulu/Aladağ 26.06.2014-1780 m., 56Dağdibi/Pozantı 12.06.2014-1390 m., 57-Calımbel/Aladağ 11.05.2014-962 m., 58- Kaledağ/Karaisalı 12.04.2014-739 m., 59Malıhıdırlı/İmamoğlu 07.04.2014-128 m., 60- Yağızlar/Sarıçam 07.04.2014-196 m., 61- Sarıçam 07.04.2014-253 m., 62- Yılankale/Ceyhan 19.09.2013-107 m., 63- Kurtkulağı/Ceyhan 19.09.2013-125 m., 64- Gölovası/Yumurtalık 18.03.2014-11 m., 65- Sugözü/Yumurtalık 18.03.2014-25 m., 66- Ağaçpınar/Ceyhan 19.09.2013-126 m., 67- Suluca/Sarıcam 15.03.2014-44 m., 68- Kürkçeler/Sarıçam 09.05.2014-97 m., 69- Kılıçlı/Sarıçam 09.04.2014-107 m., 70- Dutluca/Sarıçam 11.06.2014-125 m., 71- Tülüler/İmamoğlu 11.06.2014-210 m., 72Hacımusalı/Karaisalı 12.04.2014-239 m., 73- Çocuklar Obası/Karaisalı 12.04.2014-216 m., 74- Kevizli/Karaisalı 11.05.2014-333 m., 75Çukur/Aladağ 11.05.2014-857 m., 76- Hamidiye/Pozantı 12.06.2014-1333 m., 77- Kamışlı/Pozantı 12.06.2014-1352 m., 78Ömerli/Pozantı 09.05.2014-1083 m., 79- Fındıklı/Pozantı 12.06.2014-1200 m., 80- Akçatekir/Pozantı 12.06.2014-865 m., 81Pozant117.03.2014-768 m., 82-Belemedik/Pozant1 11.05.2014-904 m., 83- Kiralan/Karaisalı 12.04.2014-583 m., 84- Karaisalı 17.04.2014-212 m., 85- Ayakıf/Karaisalı 12.04.2014-269 m., 86- Kapıkaya/Karaisalı 16.03.2014-185 m., 87- Buçak/Karaisalı 12.04.2014-402 m., 88Kapıkaya/Karaisalı 16.03.2014-156 m., 89- Örcün/Çukurova 11.06.2014-180 m., 90- Topalak/Çukurova 11.06.2014-72 m., 91Çarkıpare/Sarıçam 07.05.2014-135 m., 92- Yüreğir 09.05.2014-46 m., 93- Vayvaylı/Yüreğir 08.04.2014-74 m., 94- Çatalpınar/Yüreğir 08.04.2014-10 m., 95- Deveçiuşağı/Ceyhan 17.11.2013-15 m., 96- Solaklı/Yüreğir 08.04.2014-10 m., 97- Doğankent/Yüreğir 08.04.2014-15 m., 98- Yolgeçen/Seyhan 05.02.2014-30 m., 99- Merkez/Adana 05.04.2014-24 m., 100- Seyhan 11.04.2014-29 m., 101- Gökçeler/Seyhan 11.04.2014-29 m., 102- Kabasakal/Seyhan 11.04.2014-127 m., 103- Fadıl/Çukurova 16.03.2014-87 m., 104- Yalmanlı/Seyhan 19.09.2013-13 m., 105- Fadıl/Çukurova 16.03.2014-87 m., 106- Kaldırım/Yumurtalık 05.02.2014-2 m., 107- Adalı/Karataş 08.04.2014-2 m., 108Adalı/Karataş 28.06.2014-1 m., 109- Kesik/Karataş 05.02.2014-5 m., 110- Yüzbaşı/Karataş 05.02.2014-6 m., 111- Yalmanlı/Seyhan 18.09.2013-36 m., 112- Yenimurat/Karataş 18.09.2013-5 m., 113- Tabaklar/Karataş 28.06.2014-2 m., 114- Tabaklar/ Karataş 18.09.2013-5 m., 115- Tuzla/Karataş 18.09.2013-2 m., 116- İnaplıhöyüğü/Karataş 28.06.2014-2 m., 117- Kapı/Karataş 28.06.2014-3 m., 118- Karataş 28.06.2014-7 m. 


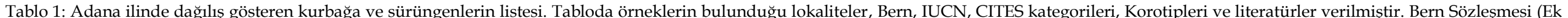

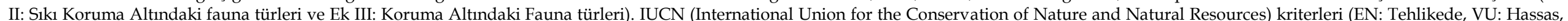

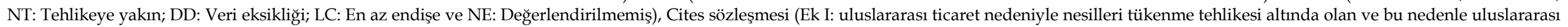
ticareti çok sıkı mevzuata tabi tutulan ve Ek II: mutlak olarak tükenme tehlikesiyle karşı karşıya olmamakla birlikte, nesillerinin devamıyla bağdaşmayan kullanımlarının önlenmesi amaçlanan

\begin{tabular}{|c|c|c|c|c|c|c|c|}
\hline FAMİLYA & TÜR & BERN & IUCN & CITES & KOROTİP & LOKALITTE & KAYNAKLAR \\
\hline Salamandridae & Salamandra infraimmaculata & III & NT & - & Güney Batı Asyatik & $4,9,18,19,22,23,29,31,57,77,78,80,82$ & $\begin{array}{l}\text { Venzmer 1922, Bird 1936, Eiselt 1966, Öz 1987, } \\
\text { Arıkan ve ark. 1990, Başoğlu ve ark. 1994, } \\
\text { Göçmen ve ark. 2008, Karahisar ve Demirsoy } \\
2012\end{array}$ \\
\hline Salamandridae & Ommatotriton vittatus & III & LC & - & Güney Batı Asyatik & $44,62,64,66$ & $\begin{array}{l}\text { Atatür 1974,_Başoğlu ve ark. 1994, Franzen ve } \\
\text { Schmidtler 2000,_Franzen, 2000, Arntzen ve } \\
\text { Olgun 2000, Göçmen ve ark. } 2008\end{array}$ \\
\hline Salamandridae & Neurergus strauchii & II & VU & - & Anadolu Endemik & -- & Schmidtler 1994, Steinfartz 1995 \\
\hline Pelobatidae & Pelobates syriacus & II & LC & - & Turan-Akdeniz & -- & $\begin{array}{l}\text { Başoğlu ve ark. 1994, Baran ve Atatür 1998, } \\
\text { Uğurtaş 2001, }\end{array}$ \\
\hline Bufonidae & Bufotes variabilis & III & $\mathrm{DD}$ & - & $\begin{array}{l}\text { Turan-Avrupa- } \\
\text { Akdeniz }\end{array}$ & $\begin{array}{l}4,5,9,16,19,20,21,22,23,38,44,46,50,57,62 \\
64,66,67,72,75,78,80,82,83,84,85,86,87,93 \\
94,102,103,107\end{array}$ & $\begin{array}{l}\text { Bird 1936, Flindt ve Hemmer 1970, Clark ve } \\
\text { Clark 1973, Başoğlu ve ark. 1994, Tosunoğlu } \\
\text { 1996, Baran ve Atatür 1998, Tosunoğlu 1999, } \\
\text { Bülbül ve Kutrup } 2007\end{array}$ \\
\hline Ranidae & Rana macrocnemis & III & LC & - & Güney Batı Asyatik & $36,55,56,76,77$ & Schmidtler ve ark. 1990, Veith ve ark. 2003 \\
\hline Ranidae & Pelophylax ridibundus s.l. & III & LC & - & $\begin{array}{l}\text { Turan-Avrupa- } \\
\text { Akdeniz }\end{array}$ & $\begin{array}{l}1,3,4,10,11,13,15,16,17,19,21,25,26,27,28 \\
30,32,33,37,38,39,40,41,42,43,44,45,47,48 \\
50,54,56,57,59,60,62,63,64,65,66,67,68,69 \\
70,74,77,78,80,81,83,84,85,88,89,92,93,96 \\
97,98,100,101,102,103,105,106,107,108,109 \\
111,112,113,116,117,118\end{array}$ & $\begin{array}{l}\text { Bird 1936, Clark ve Clark, 1973, Başoğlu ve ark. } \\
\text { 1994, Riehl ve ark. 1995, Baran ve Atatür 1998, } \\
\text { Arıan ve ark. 2000, Jdeidi ve ark. 2001, Plötner } \\
\text { ve ark. } 2001\end{array}$ \\
\hline Hylidae & Hyla savignyi & III & LC & - & Güney Batı Asyatik & $\begin{array}{l}3,4,10,11,18,19,20,21,25,32,34,37,38,41,43 \\
44,45,48,50,57,60,63,64,65,66,68,69,70,78 \\
80,81,84,89,92,93,94,96,97,98,100,101,102 \\
103,105,107,109,110\end{array}$ & Teynie 1991, Riehl ve ark. 1995, Kaya 2001 \\
\hline Geoemydidae & Mauremys rivulata & III & NE & - & $\begin{array}{l}\text { Turan-Akdeniz } \\
\text { (Turan-Balkan) }\end{array}$ & $\begin{array}{l}4,40,43,44,45,50,59,62,64,65,66,67,68,69 \\
88,92,93,96,97,98,101,105,108,109,111,112 \\
116,117,118\end{array}$ & $\begin{array}{l}\text { Bird 1936, Fritz ve Freytag. 1993, Fritz ve } \\
\text { Wischuf, 1997, Mulder 1995, Sindaco ve ark. } \\
\text { 2000, Ayaz ve ark. 2006, Ayaz ve ark. } 2008\end{array}$ \\
\hline Emydidae & Emys orbicularis & II & NT & - & $\begin{array}{l}\text { Turan-Avrupa- } \\
\text { Akdeniz }\end{array}$ & 32,106 & $\begin{array}{l}\text { Mulder 1995, Fritz ve ark. 1998, Schmidtler 1998, } \\
\text { Sindaco ve ark. } 2000\end{array}$ \\
\hline Testudinidae & Testudo graeca & II & VU & II & Turan-Akdeniz & $\begin{array}{l}2,10,32,33,34,35,36,44,45,47,50,51,57,60 \\
61,63,66,72,74,75,77,85,87,9394,102\end{array}$ & $\begin{array}{l}\text { Bird 1936, Clark ve Clark 1973, Mulder 1995, } \\
\text { Fritz ve ark. 1996, Göçmen ve ark. } 2008\end{array}$ \\
\hline
\end{tabular}


Tablo 1 (devam)

\begin{tabular}{|c|c|c|c|c|c|c|c|}
\hline FAMİLYA & TÜR & BERN & IUCN & CITES & KOROTIP & LOKALİTE & KAYNAKLAR \\
\hline Cheloniidae & Caretta caretta & II & VU & I & Kozmopolit & 117 & Atatür 1992 \\
\hline Cheloniidae & Chelonia mydas & II & EN & I & Kozmopolit & 117 & Atatür 1992 \\
\hline Trionychidae & Trionyx triunguis & II & VU & - & $\begin{array}{l}\text { Afrotropik- } \\
\text { Akdeniz }\end{array}$ & 113 & $\begin{array}{l}\text { Eiselt 1970, Sindaco ve ark. 2000, Taşkavak ve } \\
\text { Akçınar 2008, Corsini-Foka ve Masseti } 2008\end{array}$ \\
\hline Gekkonidae & Mediodactylus kotschyi & II & $\mathrm{LC}$ & - & Doğu-Akdeniz & $19,43,44,47,62,63,66,75,80,83,87,94$ & $\begin{array}{l}\text { Bird 1936, Baran ve Gruber 1982, Kasapidis ve } \\
\text { ark. 2005, Schmidtler } 1998\end{array}$ \\
\hline Gekkonidae & Hemidactylus turcicus & III & $\mathrm{LC}$ & - & Akdeniz & $62,63,75,86,95,98,102,117$ & $\begin{array}{l}\text { Bird 1936, Bodenheimer 1944, Wettstein- } \\
\text { Westersheimb 1967, Teynie 1991, Sindaco ve ark. } \\
\text { 2000, Ylldız ve ark. 2007, Göçmen ve ark. 2008, }\end{array}$ \\
\hline Agamidae & Stellagama stellio & II & LC & - & Doğu-Akdeniz & $\begin{array}{l}2,3,4,7,9,10,13,14,15,17,19,21,24,27,28,29 \\
30,35,36,37,41,42,43,44,47,48,51,53,54,55 \\
56,57,59,60,62,63,64,65,66,68,72,73,74,75 \\
76,78,79,80,81,83,85,86,87,89,90,93,94,97 \\
98,100,102\end{array}$ & $\begin{array}{l}\text { Venzmer 1922, Bird 1936, Bodenheimer 1944, } \\
\text { Clark ve Clark. 1973, Schmidtler ve Schmidtler } \\
\text { 1978, Baran ve Öz 1985, Teynie 1991, Mulder } \\
\text { 1995, Arıkan ve ark. 2000, Almog ve ark. } 2005\end{array}$ \\
\hline Chamaeleonidae & Chamaeleo chamaeleon & II & LC & II & Akdeniz & $29,50,64,70,75,93$ & $\begin{array}{l}\text { Venzmer 1922, Bird 1936, Bodenheimer 1944, } \\
\text { Baran ve ark. 1988, Sindaco ve ark. } 2000\end{array}$ \\
\hline Anguidae & Pseudopus apodus & II & $\mathrm{NE}$ & - & Turan-Akdeniz & $35,50,70,71,94,117$ & $\begin{array}{l}\text { Venzmer 1922, Bird 1936, Clark ve Clark 1973, } \\
\text { Mulder 1995, Sindaco ve ark. } 2000\end{array}$ \\
\hline Scincidae & Ablepharus budaki & III & $\mathrm{LC}$ & - & Doğu-Akdeniz & $41,43,54,65,71,86,116$ & $\begin{array}{l}\text { Göçmen ve ark. 1996, Kumlutaş 1993, Schmidtler } \\
\text { 1997b, Bosch ve ark. 1998, Schmidtler 1998, } \\
\text { Sindaco ve ark. 2000, Göçmen ve ark. } 2008\end{array}$ \\
\hline Scincidae & Ablepharus chernovi & III & $\mathrm{LC}$ & - & $\begin{array}{l}\text { Ermeni-Doğu- } \\
\text { Anadolu Endemik }\end{array}$ & 78 & $\begin{array}{l}\text { Schmidtler 1997a, Schmidtler 1998, Sindaco ve } \\
\text { ark. } 2000\end{array}$ \\
\hline Scincidae & Chalcides ocellatus & II & $\mathrm{NE}$ & - & $\begin{array}{l}\text { Akdeniz-Güney } \\
\text { Hindistan }\end{array}$ & $66,89,93,94,117$ & $\begin{array}{l}\text { Venzmer 1922, Bird 1936, Clark ve Clark 1973, } \\
\text { Baran 1977a, Sindaco ve ark. } 2000\end{array}$ \\
\hline Scincidae & Eumeces schneideri & III & $\mathrm{NE}$ & - & Güney Batı Asyatik & $47,62,63,87,89,117,118$ & $\begin{array}{l}\text { Venzmer 1922, Bird 1936, Eiselt 1940, Baran } \\
\text { 1977a, Clark ve Clark 1973, Osenegg 1989, Teynie } \\
\text { 1991, Sindaco ve ark. 2000, Ayaz ve ark. } 2011\end{array}$ \\
\hline Scincidae & Heremites auratus & III & $\mathrm{LC}$ & - & Güney Batı Asyatik & $7,63,83$ & $\begin{array}{l}\text { Clark ve Clark 1973, Baran 1977a, Sindaco ve ark. } \\
2000\end{array}$ \\
\hline Scincidae & Heremites vittatus & III & LC & - & Akdeniz & $\begin{array}{l}21,22,32,40,41,44,45,47,50,51,59,62,63,64, \\
65,66,68,69,72,73,74,80,83,85,87,90,92,93 \\
94,98,100,102,108,109,117,118\end{array}$ & $\begin{array}{l}\text { Venzmer 1922, Clark ve Clark 1973, Baran 1977a, } \\
\text { Teynie 1991, Mulder 1995, Sindaco ve ark. } 2000\end{array}$ \\
\hline Lacertidae & Anatololacerta danfordi & III & LC & - & $\begin{array}{l}\text { Güney Batt- } \\
\text { Anadolu Endemik }\end{array}$ & 然 & $\begin{array}{l}\text { Venzmer 1922, Bird 1936, Wettstein- } \\
\text { Westersheimb 1967, Eiselt ve Schmidtler 1986, } \\
\text { Schmidtler 1997a, Schmidtler 1998, Sindaco ve } \\
\text { ark. } 2000\end{array}$ \\
\hline
\end{tabular}


Tablo 1 (devam)

\begin{tabular}{|c|c|c|c|c|c|c|c|}
\hline FAMİLYA & TÜR & BERN & IUCN & CITES & KOROTIP & LOKALITE & KAYNAKLAR \\
\hline Lacertidae & Apathya cappadocica & III & LC & - & Güney Batı Asyatik & $15,35,51,56,79$ & $\begin{array}{l}\text { Bird 1936, Bodenheimer 1944, Clark ve Clark } \\
\text { 1973, Eiselt 1976, Eiselt 1979, Schmidtler 1998, } \\
\text { Sindaco ve ark. 2000, Schätti ve ark. 2005, } \\
\text { Göçmen ve ark. 2008, Ilgaz ve ark. } 2010\end{array}$ \\
\hline Lacertidae & Lacerta media & III & LC & - & Güney Batı Asyatik & $\begin{array}{l}1,2,3,4,5,9,10,21,28,35,39,41,44,48,49,50 \\
51,52,54,55,57,69,77,78,79,80,82,85,87,117\end{array}$ & $\begin{array}{l}\text { Schmidtler, 1986, Schmidtler, 1998, Sindaco ve } \\
\text { ark. } 2000\end{array}$ \\
\hline Lacertidae & Ophisops elegans & II & NE & - & Doğu-Akdeniz & $\begin{array}{l}1,2,5,8,10,12,15,21,34,36,37,38,39,40,42 \\
43,44,45,47,48,49,50,51,54,56,57,59,60,61 \\
64,70,73,74,79,80,83,85,87,88,92,93,94,96 \\
97,98,100,101,108,109,110,112,114,118\end{array}$ & $\begin{array}{l}\text { Venzmer 1922, Bird 1936, Clark ve Clark 1973, } \\
\text { Baran 1982, Tok 1992, Tok 1993, Schmidtler 1998, } \\
\text { Tok 1999, Kumlutaş ve ark. 2004, Kyriazi ve ark. } \\
2008\end{array}$ \\
\hline Lacertidae & Phoenicolacerta laevis & III & LC & - & Doğu-Akdeniz & $\begin{array}{l}4,13,14,15,16,17,19,25,29,30,32,36,40,41 \\
42,43,51,54,57,64,77,80,81,82,94,98,100 \\
101,108\end{array}$ & $\begin{array}{l}\text { Bird 1936, Bischoff ve Franzen 1993, Mulder 1995, } \\
\text { Sindaco ve ark. 2000, Göçmen ve ark. 2008, }\end{array}$ \\
\hline Lacertidae & Anatololacerta pelasgiana & III & $\mathrm{NE}$ & - & Güney-Anadolu & --- & Eiselt ve Schmidtler 1986, Schmidtler 1986 \\
\hline Lacertidae & Darevskia valentine & III & LC & - & $\begin{array}{l}\text { Ermeni-Doğu- } \\
\text { Anadolu Endemik }\end{array}$ & --- & $\begin{array}{l}\text { Schmidtler ve ark. 1990, Schmidtler 1997a, } \\
\text { Taşkavak ve Akçınar } 2008\end{array}$ \\
\hline Blanidae & Blanus cf. alexandri & III & $\mathrm{NE}$ & - & Doğu-Akdeniz & $29,38,44,51,60,69,75,83,87,93,94,102$ & $\begin{array}{l}\text { Alexander 1966, Zaloğlu 1968, Baran 1976, Bird } \\
\text { 1936, Sindaco ve ark. 2000, Yıldız ve ark. } 2009\end{array}$ \\
\hline Boidae & Eryx jaculus & III & $\mathrm{NE}$ & II & Akdeniz & 93,117 & $\begin{array}{l}\text { Bird 1936, Baran 1976, Başoğlu ve Baran 1980, } \\
\text { Teynie 1991, Sindaco ve ark. } 2000\end{array}$ \\
\hline Colubridae & Dolichophis caspius & III & LC & - & & 1,4 & Başoğlu ve Baran 1980, Sindaco ve ark. 2000 \\
\hline Colubridae & Dolichophis jugularis & II & LC & - & $\begin{array}{l}\text { Güney Batı Asyatik } \\
\text { (Iran-Anadolu) }\end{array}$ & $\begin{array}{l}10,21,28,32,35,44,45,48,49,50,57,60,62,66 \\
70,77,87,88,93,94,100,116\end{array}$ & $\begin{array}{l}\text { Bird 1936, Zinner 1972, Clark ve Clark 1973, } \\
\text { Baran 1976, Başoğlu ve Baran 1980, Tok 1992, } \\
\text { Mulder 1995, Göçmen ve ark. 2013 }\end{array}$ \\
\hline Colubridae & Eirenis aurolineatus & III & LC & - & $\begin{array}{l}\text { Güney-Anatolian } \\
\text { endemic }\end{array}$ & 83 & $\begin{array}{l}\text { Schmidtler 1997a, Sindaco ve ark. 2000, Nagy ve } \\
\text { ark. M. 2003, Nagy ve ark. } 2004\end{array}$ \\
\hline Colubridae & Eirenis barani & III & LC & - & $\begin{array}{l}\text { Güney-Anadolu } \\
\text { endemik }\end{array}$ & $9,22,31,32,51,59$ & $\begin{array}{l}\text { Schmidtler ve Schmidtler 1978, Schmidtler 1993, } \\
\text { Schmidtler 1997c, Schmidtler 1998, Venchi ve } \\
\text { Nagy ve ark. 2003, Sindaco } 2006\end{array}$ \\
\hline Colubridae & Eirenis levantinus & III & LC & - & Bat1-Akdeniz & $44,47,59$ & $\begin{array}{l}\text { Schmidtler 1993, Schmidtler 1997c, Schmidtler } \\
\text { 1998, Schmidtler, ve ark. } 2009\end{array}$ \\
\hline Colubridae & Eirenis modestus & III & LC & - & Güney Batı Asyatik & $7,16,44,56,76,77,83,87,94$ & $\begin{array}{l}\text { Bird 1936, Baran 1976, Schmidtler ve Schmidtler } \\
\text { 1978, Schmidtler 1993, Schmidtler 1997c, Başoğlu } \\
\text { ve Baran 1980, Nagy ve ark. } 2003\end{array}$ \\
\hline Colubridae & Eirenis decemlineatus & III & LC & - & E-Akdeniz & --- & $\begin{array}{l}\text { Venzmer 1922, Bird 1936, Baran 1976, Başoğlu ve } \\
\text { Baran 1998, Sindaco ve ark. } 2000\end{array}$ \\
\hline
\end{tabular}


Tablo 1 (devam)

\begin{tabular}{|c|c|c|c|c|c|c|c|}
\hline FAMİLYA & TÜR & BERN & IUCN & CITES & KOROTIP & LOKALITE & KAYNAKLAR \\
\hline Colubridae & Eirenis eiselti & III & LC & - & $\begin{array}{l}\text { Güney Doğu } \\
\text { Anadolu endemik }\end{array}$ & --- & $\begin{array}{l}\text { Schmidtler ve Schmidtler 1978, Schmidtler 1997c, } \\
\text { Sindaco ve ark. 2000, Göçmen ve ark. } 2013\end{array}$ \\
\hline Colubridae & Eirenis lineomaculatus & III & $\mathrm{LC}$ & - & Doğu-Akdeniz & -- & $\begin{array}{l}\text { Baran 1976, Schmidtler ve Schmidtler 1978, } \\
\text { Başoğlu ve Baran } 1980\end{array}$ \\
\hline Colubridae & Hemorrhois nummifer & III & $\mathrm{LC}$ & - & Turan-Akdeniz & 23 & $\begin{array}{l}\text { Bird 1936, Baran 1976, Başoğlu ve Baran 1980, } \\
\text { Mulder 1995, Sindaco ve ark. } 2000\end{array}$ \\
\hline Colubridae & Hemorrhois ravergieri & III & LC & - & Merkez Asya & 47 & Venzmer 1922, Bird 1936 \\
\hline Colubridae & Elaphe sauromates & II & $\mathrm{LC}$ & - & Turan-Akdeniz & 16,78 & Sindaco ve ark. 2000 \\
\hline Colubridae & Malpolon insignitus & III & $\mathrm{NE}$ & - & Akdeniz & $18,24,77,79,117$ & $\begin{array}{l}\text { Venzmer 1922, Bird 1936, Baran 1976, Başoğlu ve } \\
\text { Baran 1980, Mulder 1995, Sindaco ve ark. } 2000\end{array}$ \\
\hline Colubridae & Platyceps collaris & III & $\mathrm{LC}$ & - & Turan-Akdeniz & 117 & $\begin{array}{l}\text { Venzmer 1922, Baran 1976, Arıkan ve ark. 2000, } \\
\text { Schätti ve ark. } 2005\end{array}$ \\
\hline Colubridae & Platyceps najadum & II & $\mathrm{LC}$ & - & Turan-Akdeniz & $5,56,57,63,70,93,102,117$ & $\begin{array}{l}\text { Venzmer 1922, Bird 1936, Baran 1976, Sindaco ve } \\
\text { ark. 2000, Schätti ve ark. } 2005\end{array}$ \\
\hline Colubridae & Telescopus fallax & II & LC & - & Turan-Akdeniz & $59,62,117$ & $\begin{array}{l}\text { Venzmer 1922, Bird 1936, Baran 1976, Başoğlu ve } \\
\text { Baran 1980, Teynie 1991, Baran ve ark. } 2005\end{array}$ \\
\hline Colubridae & Zamenis hohenackeri & III & LC & - & Güney Batı Asyatik & 29 & $\begin{array}{l}\text { Baran 1976, Başoğlu ve Baran 1980, Sindaco ve } \\
\text { ark. } 2000\end{array}$ \\
\hline Colubridae & $\begin{array}{l}\text { Rhynchocalamus } \\
\text { melanocephalus }\end{array}$ & III & LC & - & Güney Batı Asyatik & --- & Bird 1936, Baran 1976, Başoğlu ve Baran 1980 \\
\hline Natricidae & Natrix natrix & III & LC & - & $\begin{array}{l}\text { Merkez Asyatik- } \\
\text { Avrupa- Akdeniz }\end{array}$ & 116 & $\begin{array}{l}\text { Venzmer 1922, Bird 1936, Eiselt 1970, Baran 1976, } \\
\text { Başoğlu ve Baran 1980, Olgun ve ark. } 2007\end{array}$ \\
\hline Natricidae & Natrix tessellata & II & $\mathrm{LC}$ & - & $\begin{array}{l}\text { Merkez Asyatik- } \\
\text { Avrupa }\end{array}$ & $3,15,21,39,44,50,60,74,94,108,109,112,116$ & $\begin{array}{l}\text { Venzmer 1922, Bird 1936, Baran 1976, Başoğlu ve } \\
\text { Baran } 1980\end{array}$ \\
\hline Typhlopidae & Xerotyphlops vermicularis & III & LC & - & Turan-Akdeniz & $7,16,32,44,51,56,62,64,69,83,87,93,94,97$ & $\begin{array}{l}\text { Clark ve Clark 1973, Baran 1976, Teynie 1991, } \\
\text { Arıkan ve ark. } 2000\end{array}$ \\
\hline Viperidae & Macrovipera lebetina & II & $\mathrm{NE}$ & - & Turan-Akdeniz & $35,44,47,50,62,93,94,117$ & $\begin{array}{l}\text { Venzmer 1922, Baran 1976, Başoğlu ve Baran } \\
\text { 1980, Billing ve ark. 1984, Böhme 1987, } \\
\text { Mitteilungen 1987, Osenegg 1989, Sindaco ve ark. } \\
2000\end{array}$ \\
\hline
\end{tabular}


Sonuç olarak çalışma sahası iki türün çakıștığı bir bölgededir ve morfolojik olarak net bir tür ayrımı yapmak imkânsızdır. Örnekleme alanımız B. alexandri türünün tanımlandığı (Akdam ve Akarca mh., Kozan, Adana) habitatlara oldukça yakın olduğundan ve morfolojik olarak ciddi bir fark bulunmadığından moleküler olarak analiz edilinceye kadar B. cf. alexandri olarak alınması uygun bulunmuştur. 23 yılan türünün belirlendiği bu çalışmada, Dolichophis jugularis, karasal habitatlarda, Natrix türleri ise sucul habitatlarda oldukça yaygın gözlenen yılan türleridir. Solenoglyph yılanlardan Macrovipera lebetina alanda yaygin bulunan zehirli bir yılan türümüzdür. Eirenis decemlineatus, E. lineomaculatus, E. eiselti ve Rhynchocalamus melanocephalus türleri çeşitli araştırıcilar tarafından (Venzmer 1919, Eiselt 1970, Baran 1976, Schmidtler ve Schmidtler, 1978) Adana ilinden rapor edilse de arazi çalışmaları sırasında gözlenememiştir.

Tablo 2: Türkiye ve Adana ilinde dağılış gösteren herptillerin yüzde dağılımı

\begin{tabular}{lccc}
\hline & Türkiye & Adana & $\%$ \\
\hline Kurbağalar & 31 & 8 & $25,80 \%$ \\
Kaplumbağalar & 12 & 6 & $50,00 \%$ \\
Kertenkeleler & 65 & 18 & $29,41 \%$ \\
Kör Kertenkele & 3 & 1 & $33,30 \%$ \\
Yılanlar & 57 & 23 & $40,35 \%$ \\
Toplam & $\mathbf{1 6 8}$ & $\mathbf{5 6}$ & $\mathbf{3 3 , 9 2 \%}$ \\
\hline
\end{tabular}

Günümüze kadar herpetofauna çalışmaları genellikle coğrafik sınırlar ile çalışılmıştır (Arıkan ve ark. 2000, Afşar ve Tok 2012, Cihan ve Tok 2014, Ege ve ark. 2015, Eksilmez ve ark. 2017). Orman ve Su işleri Bakanlığının 2013 yılında başlattığı envanter çalışmaları il düzeyinde projelendirildiği için son yıllarda il düzeyinde herpetofauna çalışmaları yapılmaya başlanmıştır. Literatüre göre Iğdır ilinde 27 (Tosunoğlu et al. 2010), Ağrı ilinde 35 (İğci vd. 2015), Van ilinde 37 (Yıldız vd. 2015), Bitlis ilinde 36 (Özcan ve ark. 2015) ve Karabük ilinde 24 (Kumlutaş ve ark. 2017) kurbağa ve sürüngen türünün yaşadı̆̆ 1 bilinmektedir. Bu çalışma sonucunda Adana iliinde 21 familya ait 56 tür tespit edilmiştir. Türkiye genelinde 31 kurbağa ve 137 sürüngen türü olarak toplam 168 türün mevcut olduğu bilinir. Adana ili ise 56 kurbağa ve sürüngen türü ile Türkiye herpetofaunasinın \%33,9'unu temsil etmektedir (Tablo 2)

Adana ilinde tespit edilen 56 herptil türlerinden; Bern sözleşmesine göre 19 tür Ek-II listesinde, 37 tür ise Ek-III listesinde koruma altına alınmıştır. IUCN kriterlerine göre: 1 tür EN (Endangered, Tehlike altında), 4 tür VU (Vulnerable, Hassas), 2 tür NT (Near threatened, Tehlikeye yakın), 38 tür LC (Least concern, En az endişe), 1 tanesi DD (Data deficiency, Veri eksikliği) ve 10 tür NE (Not evaluated, Değerlendirilmemiş) kategorilerinde listelenmektedir. CITES sözleşmesine göre 2 tür Ek-I listesinde, 3 tür Ek-II listesinde ve 51 tür liste dışında yer almaktadır.

Arazide yaptığımız gözlemlerde Adana ilinde evsel ve tarımsal atıkların gelişi güzel doğaya atılması çevre kirliliğine neden olmaktadır. Tarım alanlarında kullanılan tarımsal ilaçların boş kutularının su kaynaklarına atılması sucul canlılar için büyük bir tehlike arz etmektedir. Ova kurbağası, Adana ili ve çevresindeki doğal habitatlardan toplanarak ihraç edilmektedir. Bu nedenle türün ildeki doğal populasyonları her geçen gün azalmaktadır. Adana ilinde yeni tarım alanları oluşturmak, HES, taş ocakları, maden ocakları ve yol yapım çalışmalarının oluşturduğu habitat tahripleri, kimyasal atıkların, kanalizasyon ve atık suların doğaya gelişi güzel ve kontrolsüz dejarj edilmesi, anız yangınları, su kaynaklarının fazla kullanılarak kurutulması, tarla içinde kalan göletlerin kurutulması ve izinsiz hayvan toplanması (pet shoplarda kullanılmak üzere ve ticari amaçlı) amfibi ve sürüngen türlerinin günlük aktivitelerini gerçekleştirmelerini ve üremelerini etkileyen başlıca tehditlerdir.

$\mathrm{Bu}$ çalışma ile Adana ilinde dağılış gösteren 56 herptil türü ilk kez bir bütün olarak ele alınmış ve türlerin korotipleri ve il sınırları içerisinde dağıllışları tespit edilmiştir.

Teşekkür: $\mathrm{Bu}$ çalışma birinci yazarın Yüksek lisans tez çalışmasından üretilmiştir. Arazi çalışmalarına yardımlarından dolayı, Bahadır AKMAN, Abdullah Furkan ÖZCAN, Mehmet Akif BOZKURT'a, Eda BOZGÜN'e ve Harita çizimindeki yatdımından dolayı sayın Eren GERMEÇ (Çınar Mühendislik)'e teşekkürü borç biliriz. Bu çalışma, Harran Üniversitesi Bilimsel Araştırma Projeleri Koordinatörlüğü tarafından desteklenen HÜBAK 14022 nolu proje ve Orman ve Su işleri Bakanlığı Doğa Koruma ve Milli Parklar Genel Müdürlüğü tarafından yürütülen "Adana ilinin Karasal ve $\dot{I}_{c ̧} S u$ Ekosistemleri Biyolojik Çeşitlilik Envanter ve İzleme projesi" kapsamında gerçekleştirilmiştir.

\section{Kaynaklar}

Afşar, M., Tok, C. V. 2012: The herpetofauna of the Sultan Mountains (Afyon-Konya-Isparta), Turkey. Turkish journal of Zoology, 35 (4): 491-501.

Alexander, A. A. 1966: Taxonomy and Variation of Blanus strauchi (Amphisbaenia, Reptilia). Copeia, 2: 205-224.

Almog, A., Bonen, H., Herman, K., Werner, Y. L. 2005: Subspeciation or none? The hardun in the Aegean (Reptilia: Sauria: Agamidae: Laudakia stellio). Journal of Natural History, 39 (7): 567-586.

Arıkan, H., Özeti, N., Öz. M. 1990: Doğu Anadolu'dan Bitlis Salamandra salamandra (Urodela, Salamandridae) Populasyonlarının Serum Proteinleri Üzerinde Bir Ön Çalışma. Doğa-Turkish journal of Zoology, 14: 188-194

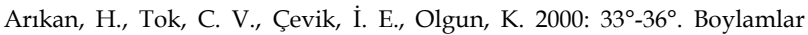
Arası Orta Toroslarin Herpetofaunası. Proje No: TBAG-1385 (195T020). Pp. III+63.

Arntzen, J. W., Olgun, K. 2000: Taxonomy of the banded newt, Triturus vittatus: morphological and allozyme data. Amphibia-Reptilia, 21: 155168.

Atatür, M. K. 1974: Güney Anadolu'da Yaşayan Triturus vittatus (Salamandridae) Populasyonları Üzerindeki Morfolojik-Taksonomik Araştırmalar. (Yüksek Lisans Raporu). Ege Üniversitesi Fen Fakültesi İlmi Raporlar Serisi, No: 188, 1-19.

Atatür, M. K. 1992: Türkiye Deniz Kaplumbağaları, Biyolojileri ve Korunmaları. T.C. Tarım ve Köy işleri Bakanlığı/Su Ürünleri Araştırma Enstitüsü Müdürlüğü, Bodrum, Seri A, Yayın No: 8, 55 pp.

Ayaz, D., Budak. A. 2008: Distribution and Morphology of Mauremys rivulata (Valenciennes, 1833) (Reptilia: Testudines: Geoemydidae) in the lake District and mediterranean region of Turkey. Turkish journal of Zoology, 32: 1-9.

Ayaz, D., Fritz, U., Tok, C. V., Mermer, A., Tosunoğlu, M., Afşar, M. 2008: Emys orbicularis (Testudinata: Emydidae), Mauremys caspica (Testudinata: Geoemydidae) ve Mauremys rivulata (Testudinata: Geoemydidae) Tatlısu Kaplumbağası Türlerinin Sistematik Revizyonu. Proje No: TBAG-2402 (103T189). Pp. XII+143.

Ayaz, D., Türkozan, O., Tosunoğlu, M., Tok, C. V., Cihan, D. 2006: Morphologic and serologic comparison of two Turkish populations of Mauremys rivulata and M. caspica. Chelonian Conservation and Biology, 5 (1): 10-17. 
Ayaz, D., Çiçek, K., Tok, C. V., Dinçaslan, Y. E. 2011: A new record of Eumeces schneideri (Daudin, 1802) in Northeastern Anatolia, Turkey. Biharean Biologist, 5 (1): 78-79.

Baran, İ. 1976: Türkiye Yılanlarının Taksonomik Revizyonu ve Coğrafi Dağılışları. TBTAK Yayınları No: 309, Türkiye.

Baran, İ. 1977a: Türkiye'de Scincidae Familyası Türlerinin Taksonomisi. Doğa Bilim Dergisi, 1: 217-223.

Baran, İ. 1977b: Türkiye'de Blanus strauchi Bedriaga 1884 türünün taksonomisi. Doga, Bilim Dergisi, 1: 192-196.

Baran, İ. 1982: Batı ve Güney Anadolu Ophisops elegans populasyonlarının taksonomik durumu. Turkish journal of Zoology, 6 (2): 19-26.

Baran, İ., Gruber, U. 1982: Taxonomische Untersuchungen An Türkischen Gekkoniden. Spixiana, 5 (2): 109-138.

Baran, İ., Öz, M. 1985: Anadolu Agama stellio (Agamidae, Reptilia) Populasyonlarının Taksonomik Araştırması. Doğa Bilim Dergisi, 9: 161-169.

Baran, İ., Kasparek., M. Öz., M. 1988: On The Occurrence and Status of the Chameleon, Chamaeleo chamaeleon, in Turkey. Zoology in the Middle East 2: 52-56.

Baran, İ., Atatür, M. K., 1998: Türkiye Herpetofaunası (Kurbağa ve Sürüngenler), Çevre Bakanlığı, Türkiye.

Baran, İ., Kumlutaş, Y., Ilgaz Ç. 2005: Geographical Distributions and Taxonomical States of Telescopus fallax (Fleischman, 1831) And Vipera barani Böhme-Joger, 1983. Turkish journal of Zoology, 29: 217-224.

Bern, 1982: Convention on the Conservation of European Wildlife and Natural Habitatswww.coe.int/en/web/conventions/full-list//conventions/treaty/104, Date of access: 12.12.2015.

Başoğlu M., Özeti N., Yılmaz, İ. 1994: Türkiye Amfibileri Genişletilmiş. 2. Baskı. Ege Üniversitesi Fen Fakultesi Kitaplar Serisi, no: 151, Türkiye.

Başoğlu, M., Baran, İ. 1980: Türkiye Sürüngenleri Kısım II. Yılanlar. Ege Üniversitesi Fen Fakültesi Kitaplar Serisi No: 81, Türkiye.

Billing, H., Schatti, B. 1984: Vorlaufige Mitteilung zum SubspeziesProblem bei Vipera lebetina. Bonn, 63-69.

Bird, C. G. 1936: The Distribution of Reptiles and Amphibians in Asiatic Turkey, With Notes on a Collection from the Vilayets of Adana, Gaziantep, and Malatya. Annals and Magazine of Natural History, 10 (18): 257-281.

Bischoff, W., Franzen, M. 1993: Einige Bemerkungen Zur Syrischen Eideche Lacerta laevis Gray, 1838 in Der Südlichen Turkei. Herpetofauna, 15 (87): 27-34.

Bodenheimer, F. S. 1944: Introduction into the knowledge of the Amphibia and Reptilia of Turkey.-Istanbul Üniversitesi Fen Fakültesi Mecmuaları Serisi, B, 9: 1-78.

Bosch, H. A. J., Bischoff, W. Schmidtler, J. F. 1998: Bemerkenswerte Reptilienfunde im Libanon. Herpetofauna, 20 (117): 19-32

Böhme, W. 1987: Nachweis Von Vipera lebetina (Linnaeus, 1758) (Serpentes: Viperidae) An Der Zentralen Südküste Der Türkei (Report of Vipera lebetina (Linnaeus 1758) (Serpentes: Viperidae) at The Central Southcoast of Turkey). Salamandra, 23 (2/3): 173-175.

Bülbül, U., Kutrup, B. 2007: Comparison of Skeletal Muscle Protein Bands among Five Populations of Bufo viridis in Turkey by SDS-PAGE, Turkish Journal of Zoology, 31: 419-422.

Bülbül U., Kurnaz, M., Eroglu, A. I., Szymura, J. M., Koç, H., Kutrup, B. 2016: First record of Bombina variegata (L., 1758) (Anura: Bombinatoridae) from Turkey. Turkish Journal of Zoology, 40: 630636.

Anonim, 2013: Çukurova Kalkınma Ajansı. Rakamlarla Adana http://www.cka.org.tr/flipbook/cka_adana/index.html,

Clark, R. J., Clark, E. D. 1973: Report on a Collection of Amphibians and Reptiles from Turkey. Occasional Papers of California Academy of Sciences, San Francisco, 104, 1-62.

Cihan, D., Tok, C. V. 2014: Akşehir-Eber kapalı havzasının Herpetofaunası. Turkish Jornal of Zoolgy 38: 234-241.

Cites, 1975: www.cites.org, Date of access: 12.12.2017.

Corsini, Foka. M., Masseti, M. 2008: On the oldest known record of the Nile Soft-shelled Turtle, Trionyx triunguis (Forskal, 1775), in the
Eastern Aegean islands (Greece). Zoology in the Middle East, 43: 108110.

Ege, O., Yakın, B. Y., Tok, C. V. 2015: Herpetofauna of the Lake District around Burdur. Turkish Journal of Zoology, 39: 1164-1168.

Eiselt, J. 1966: Ergebnisse zoologischer Samrnelreisen in der Türkei: Amphibia caudata. Annulate Natural History Museum Wien, 69: 427445.

Eiselt, J., Schmidtler, J. F. 1986: Der Lacerta danfordi-Komplex (Reptilia: Lacertidae). Spixiana, 9 (3): 289-328.

Eiselt, J. 1940: Der Rassenkreis Eumeces schneideri Daudin (Scincidae, Rept.). Zoological Anzeiger, 131: 209-228.

Eiselt, J. 1970: Ergebnisse zoologischer Sammelreisen in der Türkei: Bemerkenswerte Funde von Reptilien, I. Annulate Natural history Museum Wien, 74: 343-355.

Eiselt, J. 1976: Ergebnisse zoologischer Sammelreisen in der Türkie Bemerkenswerte Funde von Reptilen, II. Annulate Natural history Museum Wien, 80: 803-814.

Eiselt, J. 1979: Ergebnisse zoologischer Sammelreisen in der Türkei Lacerta cappadocicca Werner, 1902 (Lacertidae, Reptilia). Annulate Natural history Museum Wien, 82: 387-421.

Eksilmez, H., Altunışık, A., Özdemir, N. 2017: The Herpetofauna of Karçal Mountains (Artvin/Turkey). Biodicon, 10 (1): 1-5.

Flindt, R., Hemmer, H. 1970: Kreuzungsversuche Mit Bufo calamita, Bufo viridis viridis und Bufo viridis arabicus (Amphibia, Bufonidae). Salamandra, 6 (3/4): 94-98.

Franzen, M., Schmidtler, J. F. 2000: Verbreitung Und Ökologie Des Bandmolchs, Triturus vittatus (Jenyns, 1835), In Der Südlichen Türkei. Salamandra, Rheinbach, 36 (1): 39-58.

Franzen, M. 2000: A Distribution Record of the Banded Newt, Triturus vittatus from the Mesopotamian Plain, Southeastern Turkey. Herpetological Bulletin, 74: 26-39.

Fritz, U., Freytag, O. 1993: The distribution of Mauremys in Asia Minor, and first record of $M$. caspica caspica (Gmelin, 1774) for the internally drained central basin of Anatolia (Testudines: Cryptodira: Bataguridae). Herpetozoa, 6 (3/4): 97-103.

Fritz, U. Wischuf, T. 1997: Zur Systematik westasiatischsüdosteuropäischer Bachschildkröten (Gattung Mauremys) (Reptilia: Testudines: Bataguridae). Zoologische Abhandlungen. Staatliches Museum für Tierkunde in Dresden 49 (13): 223-260.

Fritz, U., Baran, İ., Budak, A., Amthauer, E. 1998: Some Notes on The Morphology of Emys orbicularis in Anatolia, Especially on E. O. Colchica, with The Description of A New Subspecies From Southeastern Turkey. Proceedings of the Emys Symposium Dresden 96.-Mertensiella, 10: 103-121.

Fritz, U., Bischoff, W., Martens, H., Schmidtler, J. F. 1996: Variabilitat Syrischer Landschildleroten (Testudo graeca) Sowie Zur Systematik Und Zoogeographie İm Nahen Osten Und İn Nordafrika. Herpetofauna, 18 (104): 5-14.

Göçmen, B., Akman, B. 2012: Lyciasalamandra arikani n. sp. L. yehudahi n. sp. (Amphibia: Salamandridae), two new Lycian salamanders from Southwestern Anatolia. North-Western Journal of Zoology, 8 (1): 181194.

Göçmen, B., Arıkan, H., Yalçınkaya, D. 2011: A new Lycian Salamander, threatened with extinction, from the Göynük Canyon (Antalya, Anatolia), Lyciasalamandra irfani n. sp. (Urodela: Salamandridae). North-Western Journal of Zoology, 7 (1): 151-160.

Göçmen, B., Budak., A. Karataş, A. 2008: Niğde'nin Biyolojik Çeşitliliği: Reptiller (Sürüngenler) Amfibiler (Kurbağalar). In: Aladağlar'dan Bolkarlar'a Niğde'nin Biyoçeşitliliği (Elkitabı), Karatas, A., Karatas, A. Sözen, M. (editörler), Niğde Çevre-Orman il Müdürlüğü Yayınları, No. 1, Hamle Gazetecilik ve Matbaacılık Ltd. Şti., Türkiye.

Göçmen, B., İ̆gci, N., Akman, B., Oğuz, M. A. 2013: New locality records of snakes (Ophidia: Colubridae: Dolichophis, Eirenis) in Eastern Anatolia. North-Western Journal of Zoology, 9 (2): 276-283.

Göçmen, B., Kumlutaş, Y., Tosunoğlu, M. 1996: A New Subspecies, Ablepharus kitaibelii (Bibron Borry, 1833) budaki n. ssp. (Sauria: Scincidae) From the Turkish Republic of Northern Cyprus, Turkish Journal of Zoology, 20: 397-405. 
Ilgaz, C., Arikan, H., Kumultas, Y., Avci, A. 2010: Electrophoretic comparison of blood-serum proteins of Apathya cappadocica (Sauria, Lacertidae) subspecies from Anatolia, Acta Herpetologica, 5: 207-215.

İğci, N., Göçmen, B., Akman, B., Demirsoy, A., Oğuz, M. A. 2015a: Range extension of four species of snakes (Ophidia: Eirenis, Pseudocyclophis, Platyceps) in eastern Anatolia. Biharean Biologist, 9 (2): 166-169

İğci, N., Yıldız, M. Z., Akman, B., Göçmen, B. 2015b: Ağrı İlinin Herpetofaunası. II. Ulusal Zooloji kongresi, 28-31 Ağustos 2015, Afyon.

Jdeidi, T., Bilgin, C. C., Kence, M. 2001: New Localities Extend the Range of Rana bedriagae caralitana Arikan, 1988 (Anura: Ranidae) Further West and Suggest Specific Status. Turkish Jornal of Zoolgy, 25: 153158

Karahisar, S., Demirsoy, A. 2012: The Comparison of Important Salamandra infraimmaculata Populations in Turkey by Means of Morphological, Histological and Karyotypical Characteristics. Hacettepe Journal of Biology and Chemistry Special Issue, 40: 343-352.

Kasapidis, P., Magoulas, A., Mylonas, M., Zouros, E. 2005: The Phylogeography of the Gecko Cyrtopodion kotschyi (Reptilia: Gekkonidae) in The Aegean Archipelago. Molecular Phylogenetics and Evolution, 35: 612-623.

Kaya, U. 2001: Morphological investigation of Turkish Tree Frogs, Hyla arborea and Hyla savignyi (Anura, Hylidae). Israel Jornal Zoology, 47: 123-134.

Kumlutaş, Y. 1993: Anadolu'da Ablepharus kitaibelii (Sauria: Scincidae)'nin Bireysel ve Coğrafi Variasyonu Üzerinde Araştırmalar. Doğa-Turkish Journal of Zoology, 17: 103- 115

Kumlutaş, Y., Ilgaz, Ç., Yakar, O. 2017: Herpetofauna of Karabük province. Acta Biologica Turcica, 30 (4): 102-107.

Kumlutaş, Y., Arıkan, H., Ilgaz, Ç., Kaska, Y. 2007: A New Subspecies, Eumeces schneiderii barani N. ssp (Reptilia: Sauria: Scincidae) from Turkey. Zootaxa, 1387: 27-38

Kumlutaş, Y., Öz, M., Durmuş, H., Tunç, M. R., Özdemir, A., Düşen, S 2004: On Some Lizard Species of the Western Taurus Range. Turkish Journal of Zoology, 28: 225-236.

Kyriazi, P., Poulakakis, N., Parmakelis, A., Crochet, P. A., Moravec, J., Rastegar-Pouyani, N., Tsigenopoulos, C. S., Magoulas, A., Mylonas, M., Lymberakis, P. 2008: Mitochondrial DNA reveals the genealogical history of the snake-eyed lizards (Ophisops elegans and O. occidentalis) (Sauria: Lacertidae). Molecular Phylogenetics and Evolution, 49: 795805.

Mertens, R., 1952: Amphibien und reptilien aus de turkei. Review of Faculty of Science, University of Istanbul, seri b, 17: 41-75.

Mitteilungen, K. 1987: Nacweis von Vipera lebetina (Linnaeus, 1758) (Serpentes: Viperidae) an der zentralen Sudkuste der Turkei, 23 (2-3): 173-175.

Mulder, J. 1995: Herpetological Observations in Turkey (1987-1995). Deinsea, 2: 51-66

Nagy, Z. T., Lawson, R., Joger, U., Wink, M. 2004: Molecular systematics of racers, whipsnakes and relatives (Reptilia Colubridae). Using mitochondrial and nuclear markers. Journal of Zoological Systematics and Evolutionary Research, 42: 223-233.

Nagy, Z. T., Schmidtler, J. F., Joger, U., Wink, M. 2003: Systematik der Zwergnattern (Reptilia: Colubridae: Eirenis) und verwandter Gruppen anhand von DNA-Sequenzen und morphologischen Daten. Salamandra, Rheinbach, 39(3/4): 149-168.

Olgun, K., Avc1, A., Ilgaz, Ç., Üzüm, N., Yılmaz, C. 2007: A New Species of Rhynchocalamus (Reptilia Serpentes Colubridae) From Turkey. Zootaxa, 1399: 57-68.

Osenegg, K. 1989: Die Amphibien und Reptilien Der Insel Zypern. Diplomarbeit Univ. Bonn (Thessis Of M. Sc.), 200.

Özcan, S., Üzüm, N. 2013: The herpetofauna of Madran Mountain (Aydın, Turkey). Turkish Journal of Zoology, 38: 108-113.

Özcan, A. F., Yıldız, M. Z., Akman, B., İğci, N., Sami, E., Sarıkaya, B., Göçmen, B. 2015, Bitlis İlinin Herpetofaunası Hakkında Ön Çalışma. II. Ulusal Zooloji Kongresi, 28-31 Ağustos 2015, Afyon.

Özdemir, A., Baran, İ. 2002: Research on the Herpetofauna of Murat Mountain (Kütahya-Uşak). Turkish Journal of Zoology, 26: 189-195.
Öz, M. 1987: Anadolu'daki Salamandra Salamandra'nın Taksonomi, Biyoloji ve Dağılıs Üzerine Araştırmalar. Doğa- Turkish Journal of Zoology, 11 (3): 136-154

Plötner, J., Ohst, T., Böhme, W., Schreiber R. 2001: Divergence in mitochondrial DNA of Near Eastern water frogs with special reference to the systematic status of Cypriote and Anatolian populations (Anura: Ranidae). Amphibia-Reptilia, 22: 397-412.

Riehl, C. J., Lell, J. T., Maxson, L. R. 1995: Relationships among Palearctic Hyla: Insights from Immunology. Biochemical Systematics and Ecology, 23 (3): 245-249.

Schätti, B., Stutz, A., Charvet, C. 2005: Morphologie, Verbreitung und Systematil der Schlanknatter Platyceps najadum (Eichwald, 1831) (Reptilia: Squamata: Colubrinae). Revue Suisse de Zoologie, 112 (3): 573-625.

Schmidtler, J. F., Bischoff, W. 1995: Beziehungen zwischen Lebensraum und Morphologie bei Lacerta cappadocica WERNER, 1902 in der Türkei. Die Eidechse, 6 (14): 13-21.

Schmidtler, J. J. V., Schmidtler, J. F. 1978: Eine neue Zwergnatter aus der Türkei; mit einer Übersicht über die Gattung Eirenis (Colubridae, Reptilia). Annulate Natural history Museum Wien, 81: 383-400.

Schmidtler, J. F. 1993: Zur Systematik und Phylogenie des Eirenismodestus-Komplexes in Siid-Anatolien (Serpentes, Colubridae). Spixiana, 1611: 79-96.

Schmidtler, J. F. 1994: Eine Übersicht neuerer Untersuchungen und Beobachtungen an der vorderasiatischen Molchgattung Neurergus COPE, 1862 Abhandlungen und Berichte für Naturkunde, 17: 193-198

Schmidtler, J. F. 1986: Orientalische Smaragdeidechsen: 2. Über Systematik und Synökologie von Lacerta trilineata, L. media and L. pamphylica (Sauria: Lacertidae). Salamandra, 22 (2/3): 126-146.

Schmidtler, J. F. 1997a: Anmerkungen zur Lacertiden-Fauna des südlichen Zentral-Anatolien. Die Eidechse, 8 (1): 1-9.

Schmidtler, J. F. 1997b: Die Ablepharus kitaibelii-Gruppe in Süd-Anatolien und Benachbarten Gebieten (Squamata: Sauria: Scincidae). Herpetozoa, 10 (1/2): 35-63.

Schmidtler, J. F. 1997c: Die Zwergnattern (Eirenis modestus-Komplex) des Antitaurus in Süd-Anatolien und ihre geographischen Beziehungen zur begleitenden Herpetofauna. Salamandra, 33(1): 33-60.

Schmidtler, J. F. 1998: Verbreitungsstrukturen der Herpetofauna im Taurus-Gebirge, Türkei (Amphibia: Reptilia). in: Faunistiche Abhandlungen des Stattlichen Museums Tierkunde Dresden, 21 (13): 133-148.

Schmidtler, J. F., Eiselt, J., Sigg, H. 1990: Die subalpine Herpetofauna des Bolkar-Gebirges (Mittlerer Taurus, Südtürkei). Herpetofauna, 12 (64): $11-20$.

Schmidtler, J. F., Göçmen, B., Yildiz, M. Z., Akman, B., Yalçinkaya, D. Nagy, Z. T. 2009: Rediscovery of the snake genus Eirenis on Cyprus (Reptilia: Colubridae). Salamandra, 45 (1): 15-23

Sindaco, R., Venchi, A., Carpaneto, G. M., Bologna, M. A. 2000: The reptiles of Anatolia: a checklist and zoogeographical analysis. Biogeographia, 21: 441-554.

Sindaco, R., Kornilios, P., Sacchi, R., Lymberakis, P. 2014: Taxonomic reassessment of Blanus strauchi (Bedriaga, 1884) (Squamata: Amphisbaenia: Blanidae), with the description of a new species from southeast Anatolia, Turkey. Zootaxa, (3): 311-326.

Steinfartz, S. 1995: Zur Fortpfianzungsbiologie von Neurergus crocatus und Neurergus strauchii barani. Salamandra, 31 (1): 15-32.

Taşkavak, E., Akçınar, S. C. 2008: Marine Records of the Nile Soft-shelled turtle, Trionyx triunguis from Turkey, JMBA2-Biodiversity Records, 1 -

Teynie, A. 1991: Observations Herpetologiques en Turquie 2eme Partie. Bulletin de la Société Herpétologique de France, 58: 21-30.

Tok, C. V. 1992: İç Anadolu Ophisops elegans (Sauria; Lacertidae) Populasyonlarının Taksonomik Durumu. Doğa-Turkish Journal of Zoology, 16 (4): 405-414.

Tok, C. V. 1993: Beyşehir Civarından Toplanan Ophisops elegans (Sauria: Lacertidae) Örnekleri Hakkında. Doğa-Turkish Journal of Zoology, 17 (4): 511-518. 
Tok, C. V. 1999: Reşadiye (Datça) Yarımadası Kertenkeleleri Hakkında (Gekkonidae, Agamidae, Chamaeleonidae, Lacertidae, Scincidae, Blanidae). Turkish Journal of Zoology, 23 (Ek Sayı 1): 157-175

Tosunoğlu, M. 1996: Batı Ve Güney Anadolu Bufo viridis (Anura: Bufonidae) Populasyonlarının Morfolojik ve Serolojik Yönden Karşılaştırılması. Doğa Turkish Journal of Zoology, 20 (1): 103-111.

Tosunoğlu, M. 1999: Türkiye Bufo viridis (Anura: Bufonidae) populasyonları üzerinde morfolojik, osteolojik ve karyolojik araştırmalar, Turkish Journal of Zoology, 23: 894-871.

Tosunoğlu, M., Gül, Ç., Dinçaslan, Y. E., Uysal, İ. 2010: The herpetofauna of the east Turkish province of Iğdır. Herpetozoa, 23 (1/2): 92-94.

Uğurtaş, İ. H. 2001: Variation in Pelobates syriacus of Turkey. Asiatic Herpetological Research, 9: 139-141.

Veith, M., Schmidtler, J. F., Kosuch J., Baran, I., Seitz A. 2003: Palaeoclimatic changes explain Anatolian mountain frog evolution: dispersal events. Molecular Ecology, 1(2): 185-199.

Veith, M., Göçmen, B., Sotiropoulos, K., Kieren, S., Godmann, O., Steinfartz, S. 2016: Seven at one blow: the origin of major lineages of the viviparous Lycian salamanders (Lyciasalamandra Veith and Steinfartz, 2004) was triggered by a single paleo-historic event. Amphibia-Reptilia, 37: 373-387.

Venchi, A., Sindaco, R. 2006: Annotated checklist of the reptiles of the Mediterranean countries, with keys to species identification. Part 2 Snakes (Reptilia, Serpentes). Annali del Museo Civico di Storia Naturale G. Doria", Genova, XCVIII: 259-364.

Werner, F. 1919: I. Reptilien und Amphibien aus dem Amanus-Gebirge. Archiv für Naturgeschichte, 85 (8): 130-141.

Venzmer, G. 1919: Zur Schlangenfauna Süd-Kleinasiens, speziell des cilicischen Taurus. Archiv für Naturgeschichte, 83 (11): 95-122.

Venzmer, G. 1922: Neues Verzeichnis der Amphibien und Reptilien von Kleinasien. Zoologische Jahrbücher, 46: 43-60.

Wettstein-Westersheimb, O. 1967: Ergebnisse zoologischer Sammelreisen in der Türkei: Versuch einer Klärung des Rassenkreises von Lacerta danfordi GTHR 1876, Annulate Natural History Museum Wien, 70: 345356.

Yalçınkaya, D., Göçmen, B. 2012: A new subspecies from Anatolia, Acanthodactylus schreiberi Boulenger, 1879 ataturin. ssp. (Squamata: Lacertidae). Biherian Biologist, 6 (1): 19-31.

Yıldız, M. Z., Akman, B., Göçmen, B., Yalçınkaya, D. 2009: New locality records for Turkish worm lizard, Blanus strauchi aporus (Werner, 1898) (Sauria: Amphisbaenidae) in Southeast Anatolia, Turkey. NorthWestern Journal of Zoology, 5 (2): 379-385.

Yıldız, M. Z., Göçmen, B., Akman, B., Yalçinkaya, D. 2007: New localities for Hemidactylus turcicus (Linnaeus, 1758) in Anatolia, Turkey, with notes on their morphology. North-Western Journal of Zoology, 3 (1): 24-33.

Yıldız, M. Z., İğci, N. 2015: On the occurrence of the Persian Lizard, Iranolacerta brandtii (De Filippi, 1863) (Squamata: Sauria: Lacertidae) in Eastern Anatolia, Turkey. Biharean Biologist, 9 (1): 66-71.

Yıldız, M. Z., İğci, N., Akman, B., Bulum, E., Göçmen, B. 2015: Van ilinin Kurbağa ve Sürüngen Biyoçeşitliliği, Tehditler ve Alınması Gereken Önlemler, XII. Ulusal Ekoloji ve Çevre Kongresi, 14-17 Eylül, Muğla.

Zaloğlu, Ş. 1968: Türkiye'de Blanus cinsinin (Amphisbaenidae, Reptillia) Taksonomisi. Ege Üniversitesi Fen Fakültesi İlmi, Raporlar Serisi, Izmir, 57: 3-15.

Zinner, H. 1972: Systematics and Evolution of the Species Group Coluber jugularis Linneaeus, 1758, Coluber caspius Gmelin, 1789 (Reptilia, Serpentes). Ph. D. Thesis, Hebrew University, Jerussalem.

IUCN 2017: The IUCN Red List of Threatened Species. Version 2017-3. <http://www.iucnredlist.org>. Date of Acces: 05 December 2017. 